\title{
Estudio Histológico de Boca, Esófago, Estómago e Intestino de Polystira albida (Gastropoda: Turridae)
}

\author{
Histology Study of Mouth, Esophagus, Stomach and Intestine \\ of Polystira albida (Gastropoda: Turridae)
}

Ana Laura García-López; Esther A. Uría-Galicia \& Esperanza Ortiz-Ordóñez

GARCÍA-LÓPEZ, A. L.; URÍA-GALICIA, E. A. \& ORTIZ-ORDÓÑEZ, E. Estudio histológico de boca, esófago, estómago e intestino de Polystira albida (Gastropoda: Turridae). Int. J. Morphol., 25(4):767-774, 2007.

RESUMEN: En la presente investigación se realizó la caracterización histológica del tubo digestivo de Polystira albida (Toxoglossa:Turridae) mediante microscopia óptica, utilizando ejemplares colectados en la Sonda de Campeche. Los resultados del análisis muestran que los labios, la boca y la probóscide presentan un epitelio cilíndrico simple ciliado. La cavidad bucal tiene un epitelio cilíndrico estratificado. El esófago presenta un epitelio cilíndrico simple con células glandulares granulares acidófilas (naturaleza proteica), y es el sitio donde comienza la digestión. El estómago se divide en tres regiones histológicas, y tiene dos tipos de epitelio, uno cilíndrico simple ciliado y otro cilíndrico simple; el primero está formado por abundantes células glandulares acidófilas y basófilas (naturaleza proteica y glicoproteica', respectivamente); y el segundo contiene slo células glandulares acidófilas. La glándula digestiva está constituída por adenómeros túbulo-acinosos con células glandulares acidófilas y basófilas, en diferentes grados de secreción y los conductos presentan un epitelio cilíndrico ciliado con células glandulares de ambos tipos. El intestino se divide en cinco regiones histológicas, la primera presenta un tiflosol con dos tipos de epitelio, cilíndrico simple y cilíndrico simple con chapa estriada; y el resto del tracto tiene un epitelio cilíndrico simple ciliado con células glandulares granulares acidófilas y pliegues de diferentes tamaños que aumentan o reducen la cavidad del conducto. Se concluye que existen diferencias, principalmente en la región anterior del tubo digestivo (cavidad bucal, esófago y estómago), con respecto a las descripciones generales realizadas para la subclase Prosobranchia.

PALABRAS CLAVE: Tracto digestivo; Conoidea; Turridae; Polystira albida.

\section{INTRODUCCIÓN}

Polystira albida (Perry, 1811) perteneciente a la familia Turridae, se encuentra dentro del suborden Toxoglossa, que se caracteriza por presentar hábitos alimenticios de tipo carnívoro, mediante un sistema radular modificado hacia un mecanismo inyector de veneno, cuya morfología funcional y evolución, han sido estudiados por Shimek \& Kohn (1981), Sysoev \& Kantor (1987) y Kantor \& Taylor (1991). Con respecto a la organización general y la descripción anatomohistológica del sistema digestivo de prosobranquios, existen trabajos realizados por diversos autores como Graham (1939, 1941, 1966); Fretter \& Graham (1962, 1976); Martoja (1964), Owen (1966 a,b), Hyman (1967) y Voltzow (1994); Taylor \& Miller (1990) comparan el sistema digestivo anterior de túrridos, cónidos y terébridos. Sin embargo, los estudios que se han realizado a la fecha, se han enfocado a las características anatómicas y microscópicas del aparato del veneno y la rádula de algunas especies de conoideos (Marsh,
1977; Marshall et al. 2002, entre otros), existiendo una carencia en lo relacionado a estudios histológicos del tubo digestivo de los túrridos como P. albida, por lo que el presente trabajo tiene la finalidad de aportar elementos histológicos que permitan comprender algunos aspectos de la fisiología de la alimentación de esta especie.

\section{MATERIAL Y MÉTODO}

Los ejemplares de P. albida analizados, fueron proporcionados por el Dr. Edgar P. Heimer de la Cotera del Centro de Neurobiología de la UNAM. Los ejemplares fueron colectados en la Sonda de Campeche (19 ${ }^{\circ} 53^{\prime} 03^{\prime \prime}$ Latitud Norte y a $90^{\circ} 59^{\prime} 40^{\prime \prime}$ Longitud Oeste) a una profundidad de 100 metros, aproximadamente. 
Se colectaron ejemplares adultos, se desconcharon y fijaron en una solución de formol al $10 \%$ en regulador de fosfatos. Los organismos completos se lavaron en agua corriente, para eliminar el exceso de fijador, deshidratando posteriormente con cambios graduales de alcohol de menor a mayor concentración, comenzando con alcohol $25^{\circ}$ hasta llegar a alcohol absoluto; posteriormente fueron transparentados con un cambio de alcohol absoluto-xileno. La inclusión se realizó utilizando parafina Merck ${ }^{\circledR}$ de diferentes puntos de fusión, finalizando con la de $56^{\circ}$ a $58^{\circ} \mathrm{C}$. Con un micrótomo 820 Rotary American Optical se realizaron cortes seriados de $8 \mu \mathrm{m}$. Las laminillas se desparafinaron y se tiñeron con las técnicas de Hematoxilina-Eosina (Uría y Mora, 1996) y Tricrómica de Masson (Martoja \& Martoja, 1970). Una vez montadas con Entellan Merck $₫$, se obtuvieron microfotografías en un fotomicroscopio Leica ATC 2000, MPS 30.

\section{RESULTADOS}

Para caracterizar histológicamente las regiones del tubo digestivo de P. albida, se consideraron los criterios descriptivos de Hyman y Voltzow.

Labios, boca y probóscide. Están constituidos por un epitelio cilíndrico simple ciliado, en el caso de los labios sin pliegues, en tanto que en la región de la boca y la probóscide, se encuentran pliegues altos y anchos para el primer caso, y bajos y anchos para el segundo. El epitelio descansa sobre una membrana basal fina rodeada por una lámina propia de tejido conjuntivo laxo con células propias, entre el cual se encuentran escasas fibras musculares lisas (Fig. 1A, $1 \mathrm{~B}, 1 \mathrm{C})$.

Cavidad bocal. Se observa un epitelio cilíndrico estratificado que descansa sobre una membrana basal fina, a continuación la lámina propia de tejido conjuntivo laxo, se continúa con una capa de abundantes fibras musculares lisas (Fig. 1D).

Esófago. Está formado por un epitelio cilíndrico simple, con abundantes células glandulares granulares acidófilas de naturaleza proteica, evidenciadas con la Técnica Tricrómica de Masson. El epitelio forma pliegues bajos y anchos que descansan sobre una membrana basal fina y escaso tejido conjuntivo laxo, que forma la lámina propia; a continuación, se encuentra una capa gruesa de fibras musculares lisas. Hacia la parte final, se forma una válvula que se proyecta hacia el interior de la primera región del estómago; las células glandulares granulares del epitelio varían en cantidad a lo largo de ésta (Fig. 2A).
Estómago. Está formado por tres regiones: la primera presenta un epitelio cilíndrico simple ciliado, que forma pliegues uniformes, bajos y anchos con abundantes células glandulares unicelulares de dos tipos: unas granulares acidófilas de secreción proteica, y otras de citoplasma homogéneo que, al teñirse de azul con la técnica Tricrómica de Masson, indican que su composición química es de glucoproteínas ácidas. La segunda y tercera regiones están constituidas por un epitelio cilíndrico simple que forma abundantes pliegues altos y anchos; en la segunda región, sólo se encuentran abundantes células glandulares granulares de naturaleza proteica; y en la tercera región, éstas están ausentes. El epitelio de las tres regiones del estómago, descansa sobre una membrana basal fina y a continuación está la lámina propia formada por tejido conjuntivo laxo, después de la cual hay una capa formada por abundantes fibras musculares lisas (Fig. 2B, 2C, 2D).

Glándula digestiva. Está formada por conductos y abundantes adenómeros túbulo-acinosos que se encuentran en diferentes etapas de secreción. Mediante la técnica Tricrómica de Masson se observaron dos tipos de células: las primeras y más abundantes tienen forma cilíndrica, con un núcleo de posición basal y secreción granular abundante de naturaleza proteica; el segundo tipo es escaso, de forma piramidal con núcleo basal y secreción de naturaleza glicoproteica. Alrededor de los adenómeros se observan abundantes fibras musculares lisas y tejido conjuntivo laxo con células propias. Entre los adenómeros se encuentran conductos que desembocan en el estómago revestidos por un epitelio cilíndrico simple ciliado, entre el cual se localizan los dos tipos celulares de los adenómeros, con la diferencia que en los conductos las células basófilas están en mayor proporción; éstas células descansan sobre una membrana basal evidente y a continuación tejido conjuntivo laxo (Fig. 3A, 3B).

Intestino. Está formado por cinco regiones, que se diferencian por el tipo de pliegues que forma el epitelio y la presencia o ausencia de cilios y células glandulares granulares acidófilas. El epitelio descansa sobre una membrana basal fina, una lámina propia de tejido conjuntivo laxo y una capa fina de fibras musculares lisas. En la primera región se forma un tiflosol formado por dos conductos, el externo presenta un epitelio cilíndrico simple, y el interno también pero con chapa estriada; ambos tipos de epitelio forman pliegues altos y delgados que obliteran la luz. En la segunda región, se encuentra un epitelio cilíndrico simple ciliado con células glandulares granulares, es una zona de transición, en donde los pliegues son bajos y anchos, altos y delgados y otros más largos y delgados. En la tercera región, se observan células glandulares granulares acidófilas entre el epitelio, y se forman principalmente pliegues altos y anchos. La cuarta región se diferencia porque se forma una cavidad muy 
amplia que posteriormente se reduce, y los pliegues son de grosor y altura variables. La quinta región presenta un epitelio cilíndrico simple ciliado alto con células glandulares
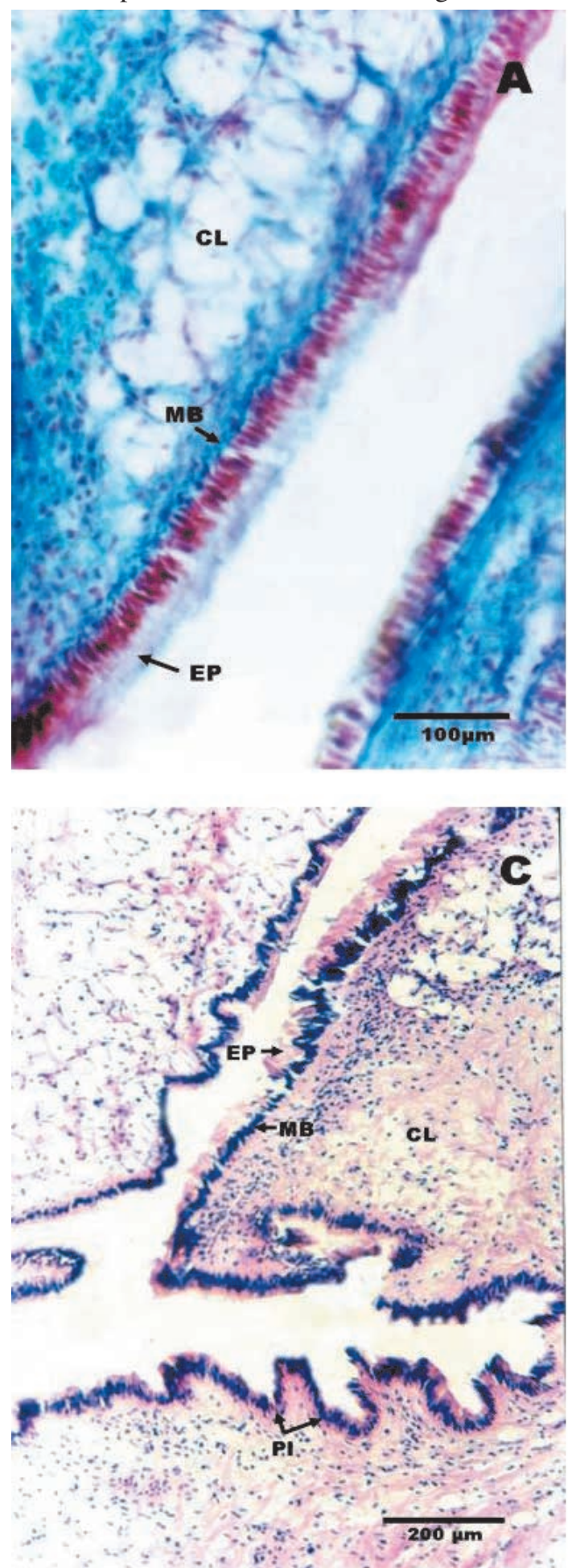

granulares acidófilas, pero no forma pliegues. El intestino finalmente termina su curso recto al dar un giro de $180^{\circ} \mathrm{y}$ desembocar hacia la cavidad paleal (Fig. 3C, 3D y 4A-D).
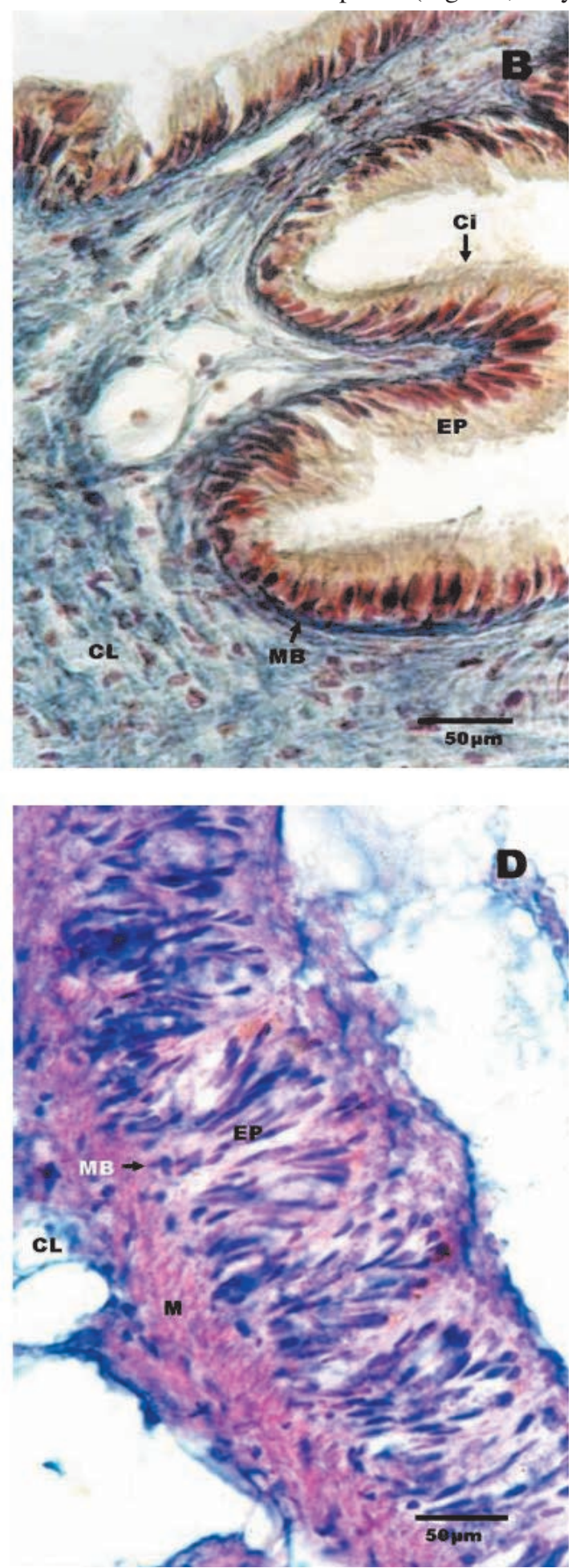

Fig. 1. Polystira albida (Gastropoda: Turridae). A. Labios; B. Boca; C. Probóscide; D. Cavidad bucal; Ep. Epitelio; Ch. Chapa estriada; MB. Membrana basal; M. Fibras musculares lisas; CL. Conjuntivo laxo; Ci. Cilios; Pl. Pliegues; v. Válvula esofágica; CG. Células glandulares; CA. Células glandulares acidófilas; CB. Células glandulares basófilas. 

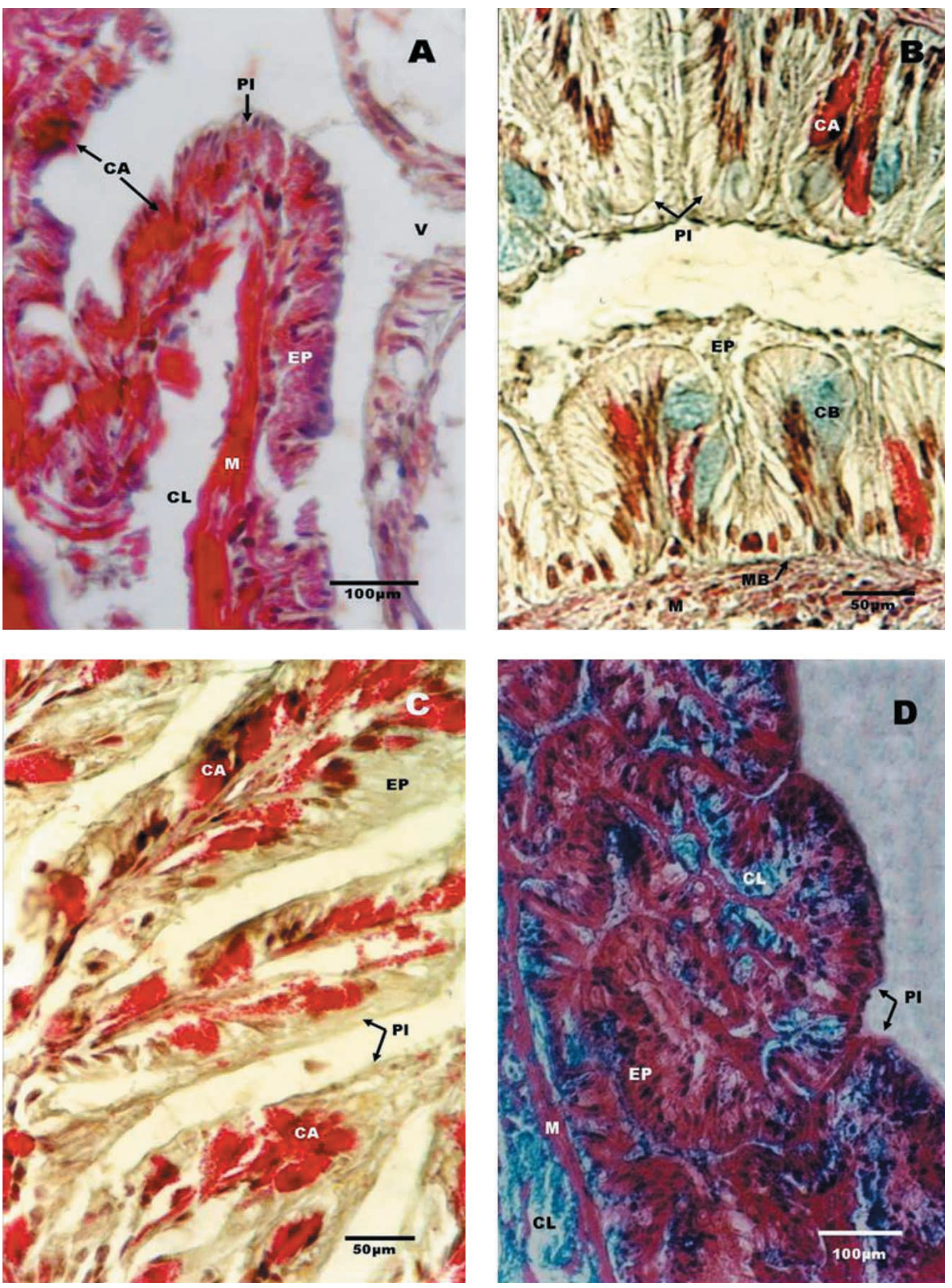

Fig. 2. Polystira albida (Gastropoda: Turridae). A. Esófago; B. Estómago, primera región; C. Estómago, segunda región; D. Estómago, tercera región. Ep. Epitelio; Ch. Chapa estriada; MB. Membrana basal; M. Fibras musculares lisas; CL. Conjuntivo laxo; Ci. Cilios; Pl. Pliegues; v. Válvula esofágica; CG. Células glandulares; CA. Células glandulares acidófilas; CB. Células glandulares basófilas. 

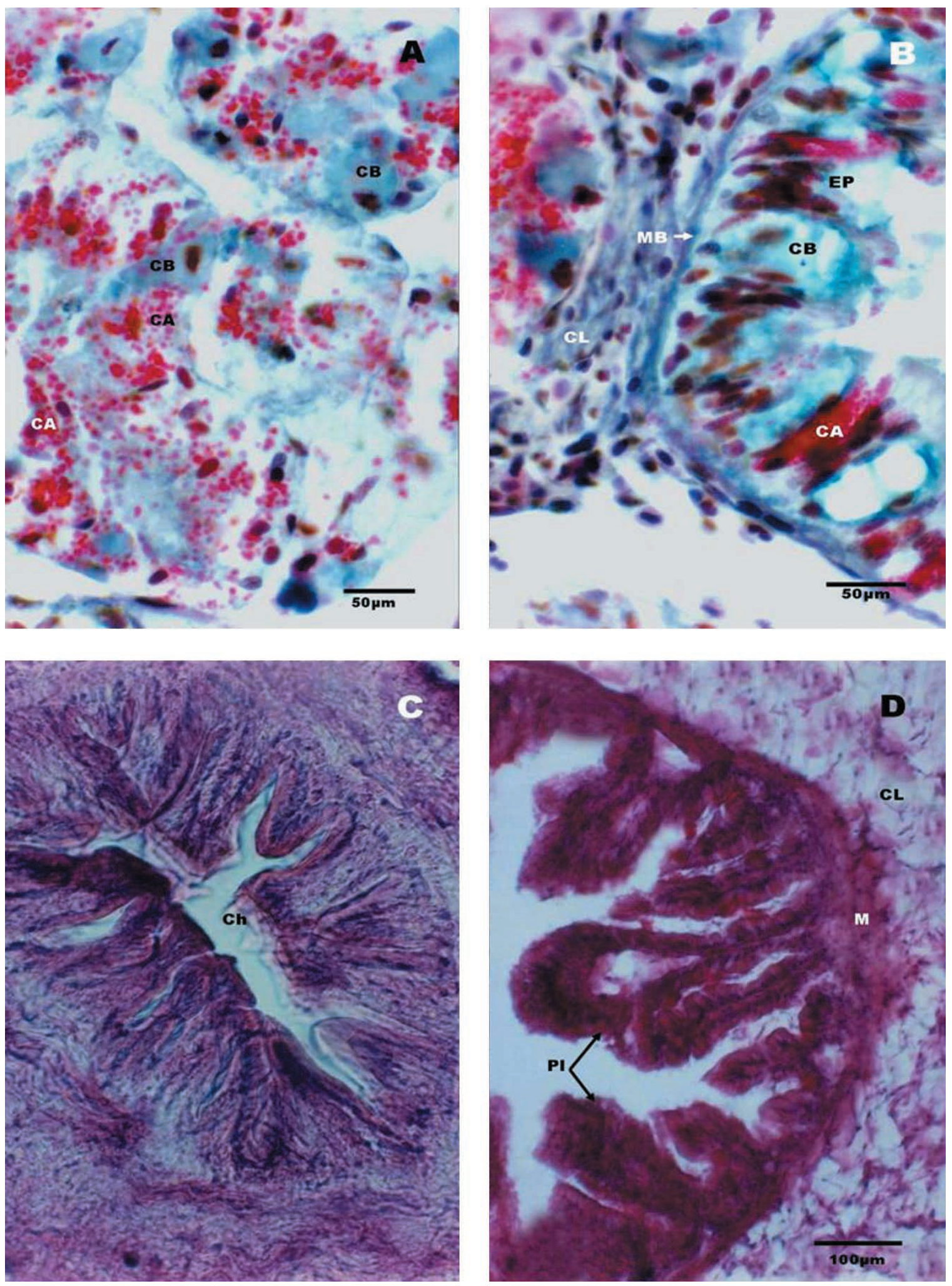

Fig. 3. Polystira albida (Gastropoda: Turridae). A. Glándula digestiva (adenómeros); B. Glándula digestiva (conductos); C. Intestino (primera región, tiflosol); D. Intestino (segunda región, pliegues de diferentes tamaños). Ep. Epitelio. Ch. Chapa estriada; MB. Membrana basal; M. Fibras musculares lisas; CL. Conjuntivo laxo; Ci. Cilios; Pl. Pliegues; v. Válvula esofágica; CG. Células glandulares; CA. Células glandulares acidófilas; CB. Células glandulares basófilas. 

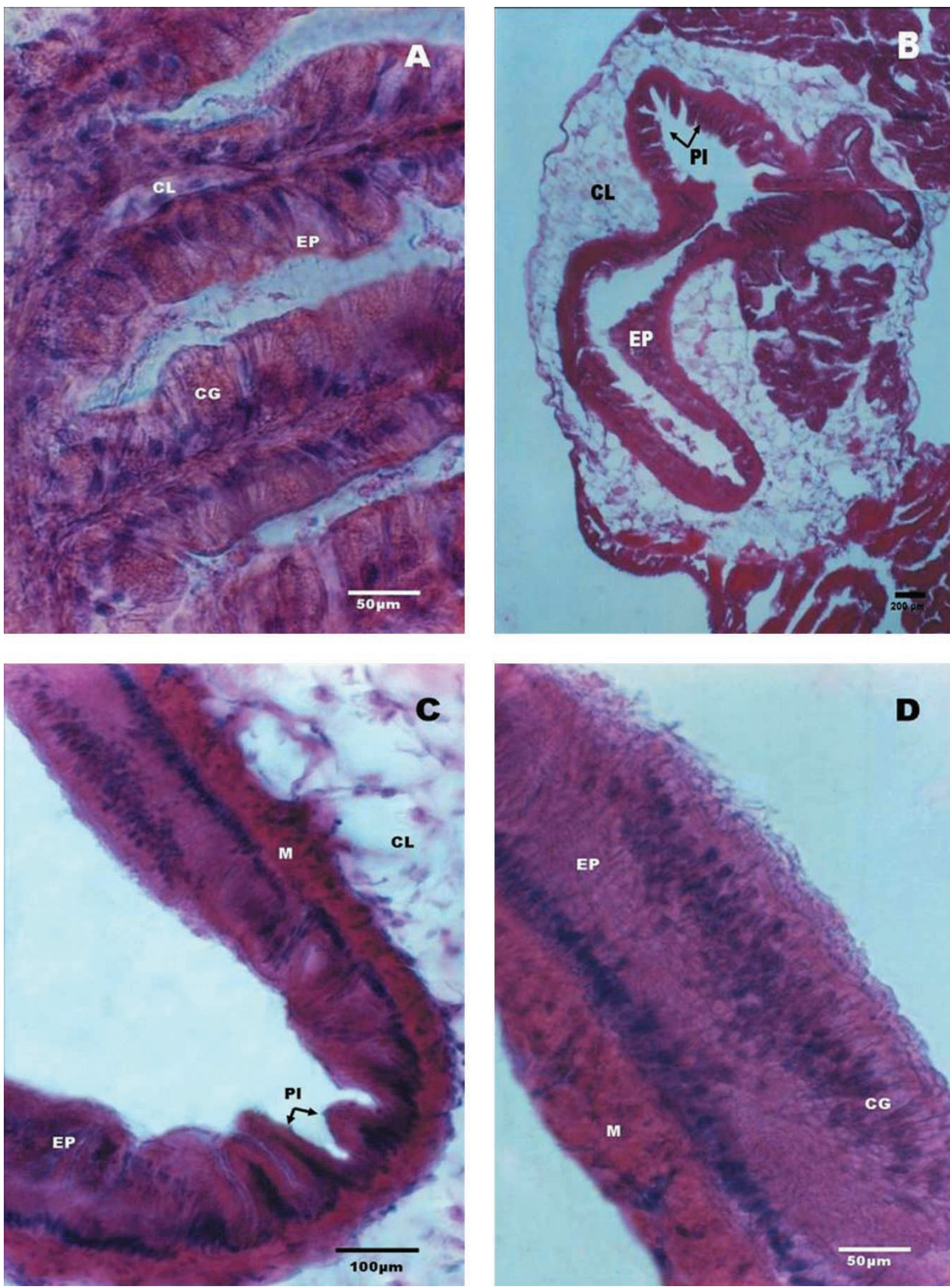

Fig. 2. Polystira albida (Gastropoda: Turridae). A. Intestino (tercera región, células glandulares granulares acidófilas); B. Intestino (cuarta región, cavidad del conducto); C. Intestino (cuarta región, zona de transición); D. Intestino (quinta región). Ep. Epitelio; Ch. Chapa estriada; MB. Membrana basal; M. Fibras musculares lisas; CL. Conjuntivo laxo; Ci. Cilios; Pl. Pliegues; v. Válvula esofágica; CG. Células glandulares; CA. Células glandulares acidófilas; CB. Células glandulares basófilas. 


\section{DISCUSIÓN}

En cuanto a las primeras regiones del tubo digestivo de $P$. albida, en especial cavidad bucal y esófago, existen diferencias importantes, con respecto a las características descritas para los prosobranquios por Hyman, Fretter \& Graham (1976) y Voltzow, ya que en esta especie, la presencia de un epitelio cilíndrico estratificado en la cavidad bucal, le confiere una función de protección y conducción (Gartner \& Hiatt, 2001), necesaria para la inyección y conducción del veneno durante la alimentación. La presencia de células glandulares granulares de naturaleza proteica en la región del esófago, indican el comienzo del proceso de degradación del alimento que, junto con las enzimas salivales, son transportados hacia el estómago por la peristalsis impartida por las paredes formadas por fibras musculares lisas (Fretter \& Graham, 1976). Como se menciona para otros Neogasteropodos carnívoros, las áreas ciliares comúnmente se pierden cuando hay cierta simplificación a nivel del tracto digestivo (Wilbur \& Yongue, 1966), lo cual explica la ausencia de cilios en el esófago y en la mayor parte del estómago. La ausencia de cutícula y la presencia de cilios en las células epiteliales del estómago, están relacionadas con el tipo de alimentación reportado para la mayoría de los túrridos, que consiste principalmente de poliquetos (Shimek, 1977), los cuales se caracterizan por estar cubiertos por una cutícula de naturaleza colágena fina y fibrosa (Barnes \& Ruppert, 1995), lo cual les confiere una consistencia blanda. Las características histológicas encontradas en las tres regiones del estómago, indican que en cada una de ellas, se realizan diferentes funciones, como son: la descomposición de partículas de alimento en otras más pequeñas, llevada a cabo por la ac- ción enzimática adicional de las células glandulares de composición glicoproteíca y la absorción de nutrientes, de tal manera, que las partículas pasan hacia la glándula digestiva, en donde se llevan a cabo la secreción de enzimas digestivas, absorción y almacenamiento de nutrientes y la liberación de partículas no digeribles, que desembocan en el intestino para ser eliminadas (Voltzow).

El intestino de $P$. albida se divide en varias regiones de acuerdo a la presencia de cilios, células glandulares y a la formación de pliegues que aumentan o disminuyen la luz del conducto. Sin embargo, los procesos que se llevan a cabo, como son la absorción de nutrientes, la acción enzimática y la propulsión de moco en la superficie epitelial, realizada mediante las corrientes ciliares, inducen finalmente al empaquetamiento y transporte de las partículas de desecho, y son similares en general a las descritas para otros prosobranquios (Hyman y Voltzow).

\section{AGRADECIMIENTOS:}

Agradecemos a las profesoras del Laboratorio de Histología del Departamento de Morfología de la ENCB del I.P.N., la Q.B.P. Margarita Montuoso Gazca, por su participación en el establecimiento del contacto con el Dr. Edgar P. Heimer de la Cotera, del Centro de Neurobiología de la UNAM, quien nos proporcionó los ejemplares con los cuáles se llevó a cabo el presente estudio histológico y a la Bióloga María del Carmen Mora Vázquez del Mercado por sus observaciones y sugerencias.

GARCÍA-LÓPEZ, A. L.; URÍA-GALICIA, E. A. \& ORTIZ-ORDÓÑEZ, E. Estudio histológico de boca, esófago, estómago e intestino de Polystira albida (Gastropoda: Turridae). Int. J. Morphol., 25(4):767-774, 2007.

SUMMARY: In the present investigation it was realized a histological characterization of the digestive tract of Polystira albida (Toxoglossa: Turridae), by using optic microscopy of specimens collected in Sonda de Campeche. Results of analysis show that lips, mouth and proboscis present a simple columnar epithelium with cilia. Buccal cavity has a stratified columnar epithelium. Esophagus presents a simple columnar epithelium with acidophilic granular glandular cells (proteic nature), and it is the place where digestion starts. Stomach is divided in three histological regions that have two epithelial types, simple columnar with cilia and without one; the first is formed by a lot of acidophilic and basophilic glandular cells (proteic and glycoproteic nature respectively), and the second only contains acidophilic glandular cells. Digestive gland is constituted by tubule-acinous adenomers with acidophilic and basophilic glandular cells in different grades of secretion, and ducts have simple columnar epithelium with cilia and scarcely glandular cells. Intestine is divided in five histological regions, the first presents atyphlosole with two types of epithelium, simple columnar with stratified border; the rest of the tract has simple columnar epithelium with cilia, acidophilic granular glandular cells and folds of different sizes that increase or reduce the cavity duct. Based on previous this, we conclude that in this study exist differences principally in front region of digestive tract (buccal cavity, esophagus and stomach) compared to general descriptions realized for Prosobranchia subclass. 


\section{REFERENCIAS BIBLIOGRÁFICAS}

Barnes R. D. \& Ruppert, E. E. Zoología de los Invertebrados. $6^{\mathrm{a}}$. ed. Mc GRaw-Hill Interamericana, México, 1995. pp. 380-411.

Fretter, V. \& Graham, A. British Prosobranch Molluscs. Royal Society, London, 1962.

Fretter, V. \& Graham, A. A Functional Anatomy of Invertebrates. Academic Press, London, New York, 1976.

Gartner, L. P. \& Hiatt, J. L. Texto Atlas de Histologia. Mc Graw-Hill, México, 2001.pp. 84.

Graham, A. On the Structure of the alimentary canal of stylebearing prosobranchs. Proceedings of Zoology, Society, London., 109:75-112, 1939.

Graham, A.The oesophagus of the stenoglossan prosobranchs. Proceedings of the Royal Society Edinburg., 61:1-23, 1941.

Graham, A.The fore-gut of some marginellid and cancellariid prosobranchs. Studies of Tropical Oceanography, Miami., 4:134-51, 1966.

Hyman, L. H. Prey Capture Chapter. In: The Invertebrates. Mollusca 1. Mc Graw-Hill Book Company, 1967. V. 6. pp. 207-47.

Kantor, YI. \& Taylor, J. D. Evolution of the toxoglossan feeding mechanism: New information of the use of the radula. J. Molluscan Studies, 57:129-34, 1991.

Marsh, H. The radular apparatus of ConusJ. of Molluscan Studies, 43:1-11, 1977.

Marshall, J.; Kelley, W. P.; Rubakhin, S. S.; Bingham, J. P.; Sweedler J. V. \& Gilly, W. F. . Anatomical correlates of venom production in Conus californicus. Biological Bulletin, 203:27-41, 2002.

Martoja, M. Contribution a l'etude de l'appareil digestif et de la digestión chez les gastéropodes carnivores de la famille des nassaridés (Prosobranches sténoglosses). Cellule, 64:235-334,1964.

Martoja, R. \& Martoja, M. Técnicas de Histología Animal. Toray Masson, Barcelona, 1970.
Owen, G. Digestión. In: Wilbur, K. and C.M. Yonge (Eds.). Physiology of Mollusca. Academic Press, New York. 1966a. V. 2. pp. 53-96.

Owen, G. Feeding. In Wilbur, K. \& Yonge C. M. (Eds.). Physiology of Mollusca. Academic Press, New York. 1966b. Vol. 2. pp. 1-51.

Shimek, R. L. Resource Utilization and Natural History of some Northeastern Pacific Turridae. Ph. D. Dissertation, University of Washington, Seattle, 1977.

Shimek, R. L. \& Kohn, A. J. Functional morphology and evolution of the toxoglossan radula. Malacologia, 20:423-38, 1981.

Sysoev, A. V. \&. Kantor, Y. I. Deep-sea gastropods of the genus Aforia (Turridae) of the Pacific: species composition, systematics, and functional morphology of the digestive system. Veliger., 30:105-26, 1987.

Taylor, J. D. \& Miller, J. A. A new type of gastropod proboscis: The foregut of Hastula bacillus (Gastropoda: Terebridae). J. of Zoology., 220:603-17, 1990.

Uría, E. \& Mora, C. Apuntes para el Curso Teórico Práctico de Histología Animal. IPN, México, 1996.

Voltzow, J. Gastropoda: Prosobranchia. In: Harrison, F.W. \& Kohn, A. J. (Eds.). Microscopic Anatomy of Invertebrates. Vol. 5. Mollusca I. Wiley-Liss, New York, 1994. pp. 112-252.

Wilbur, K. M. \& Yonge, C. M. Physiology of Mollusca. Academic Press, London, New York, 1966. V. II.

Dirección para correspondencia:

Prof. Ana Laura García-López

Laboratorio de Histología

Departamento de Morfología

Instituto Politécnico Nacional

Escuela Nacional de Ciencias Biológicas

Prol. de Carpio y Plan de Ayala

11340, México D.F

MÉXICO

Email: dipurena@yahoo.com.mx

Recibido : 25-10-2006

Aceptado: 26-08-2007 